tion ..." (i.e. taxon); “. . . third alternative ..." - and the chapters are short. The bibliography is excellent; here Feduccia refuses to "talk down" to the reader and quotes every reference, not just "further reading". However, the illustrations although numerous are often disappointing. They include black and white photographs of specimens and localities, and a number of frankly mediocre original drawings by several hands, the low standard of which is emphasized by some of the splendid and

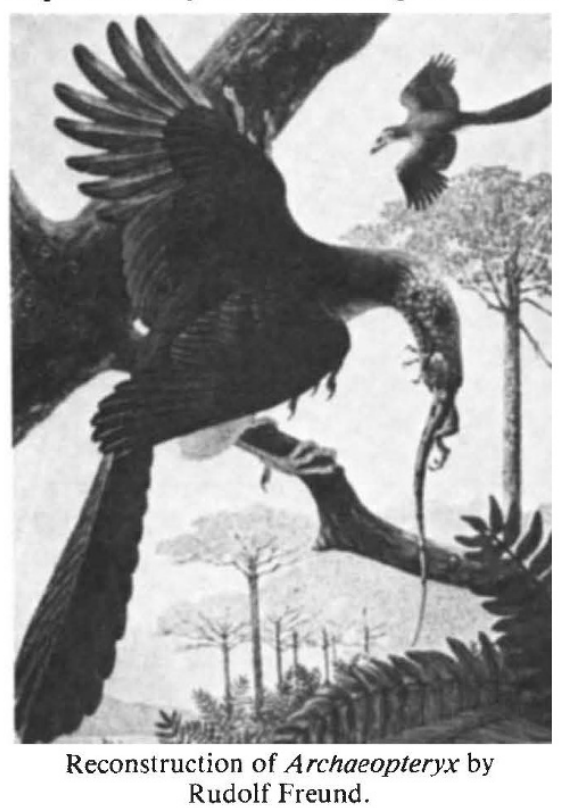

famous restorations by Heilmann, Charles Knight and others with which they appear. Many of these cry out for their original colours. Presumably the decision to exclude the use of colour was the publisher's rather than the author's; nevertheless I imagine that it will affect sales adversely. This is a pity as the book is otherwise well produced and certainly deserves an audience.

Alec Panchen, a vertebrate palaeontologist, is Reader in Vertebrate Zoology at the University of Newcastle upon Tyne.

\section{Gorillas on a tightrope}

\section{Alison Jolly}

The Natural History of the Gorilla. By A. F. Dixson. Pp.202. ISBN 0-297-77895-1. (Weidenfeld \& Nicolson: 1981.) £16.50. To be published in the USA by Columbia University Press.

IF YOU want to know about gorillas, you need this book. Alan Dixson has summarized the present state of knowledge about all aspects of gorillas' biology from anatomy to conservation. Furthermore, he writes in a lucid, factual style which presents the information clearly to anyone from fifth form to professorial status, without either talking down or jazzing up.
The drawings (by Dixson himself) add both clarity and charm.

The book has several strengths. First, it deals equally with the results of laboratory work and results from the field. Dixson's own studies range from laboratory analysis of primate hormones and sexual behaviour, through the testicular atrophy of several adult male silverbacks in zoos (including Guy at London), to making field censuses of gorilla populations. He is thus well placed to appreciate both sides of the story. A second strength is the balance achieved between generalization and data from individual studies. In the chapter "How Close to Man?", he manages to explain quickly many of the bases of primate classification, sum up the evidence which suggests man's close relationship to gorilla and chimpanzee and the more distant relationship of these three African species to orang-utans, and yet include the divergent studies which indicate Asiatic, rather than African, origins for man. Similarly, when he describes wild populations, he includes data showing differences between the three gorilla subspecies, and even between western and eastern Virunga Volcanoes, adding appropriate caution about sample size. In a popular book, it is unusual to avoid generalizations about "the gorilla" meaning ten or twenty individuals on Mount Visoke.

Finally, Dixson covers the whole scope of the literature from Hanno (fifth century BC) up to 1980 . This enables him to deal fairly with such experiments as Yerkes' on Congo (1926-1928), which is still one of the most complete accounts of a gorilla's problem-solving, as well as Redshaw's (1978) splendid Piagetian study of the development of infant gorilla intelligence. The conservation account is also up to date, to the death of Digit and others who had their heads and hands chopped off for tourist souvenirs.

The main reservation I have is that Dixson does not pursue his synthesis of detail quite far enough for my taste. I looked for a discussion of the relation of gorilla leaf-eating to metabolism, ranging and social structure, and comparison with the frugivorous orang and chimp. All the pieces are there, but Dixson does not explicitly link them up; similarly, reproductive strategy is split into several different chapters. This is clearly his choice - he gives us the data without fashionable theorizing, but he is better placed than most of us to deal with such theories.

I could also do with slightly more drama in the final chapter on conservation perhaps some of Dian Fossey's emotion over Digit, or Alan Goodall's encounters with poachers in The Wandering Gorillo (Collins, 1979). Instead, Dixson has chosen restraint. Perhaps he is right that estimates of the remaining wild populations and their possible or likely extinction are even more horrifying.

The whole question of how to balance professional against popular appeal bedevils primate studies. In the circumstances Alan Dixson's summary of the natural history of the gorilla for such a wide audience is laudable. Scholarly balance may seem faint praise until you add that it is balance on a very thin tightrope indeed.

Alison Jolly is temporarily in the School of Cultural and Community Studies, University of Sussex.

\section{Lure of the shore}

\section{J.T. Enright}

Intertidal Invertebrates of California. By Robert H. Morris, Donald P. Abbott and Eugene C. Haderlie with 31 contributors. Pp.920. ISBN 0-8047-1045-7. (Stanford University Press: 1980.) \$45 US only.

This is a book for those who find the California shoreline at low tide a place of beauty, wonder and interest, and who want information on the common animals that live there. [Preface].

THE west coast of North America has one of the most diverse temperate-latitude intertidal faunas in the world. In California that fauna provides research material for dozens of marine laboratories and learning material for hundreds of high schools, colleges and universities. Intertidal Invertebrates of California is aimed at that limited - some might say, provincial audience, but it could conceivably also lure naturalists from the entire world to view and study this showplace of diversity. Whether or not it eventually has that sort of incidental success, there is no question about its value and importance for the intended audience: every biologist, professional or amateur, who ventures into the California intertidal zone for the first - or the ten-thousandth - time should have this volume available.

Thanks to a grant from The David and Lucille Packard Foundation, the price is such that most users will be able to purchase their own copies. Even a first glance at the 200 photographic plates - all but three of them in colour, most with four to six separate portraits of the animals will persuade the prospective buyer that this book is a bargain. The majority of the photographs were taken by Morris, but nearly 50 other naturalists contributed to the handsome illustrations. This portion of the book will be particularly treasured by all who find the "shoreline . . . a place of beauty [and] wonder".

With the photographs as the bait, Abbott and Haderlie, together with 31 other contributors, have provided nearly 700 pages of text, bibliography and index for those "who want information". Some 750 species are treated in detail in the 24 chapters. For each of entry, the text provides the classification of the animal; a morphological description, including 